\title{
Introduction to the Special Issue on "Hinduism: Historical Perspectives and Contemporary Developments"
}

\author{
Amiya P. Sen
}

check for updates

Citation: Sen, Amiya P. 2021. Introduction to the Special Issue on "Hinduism: Historical Perspectives and Contemporary Developments" Religions 12: 85. https://doi.org/ $10.3390 /$ rel12020085

Received: 30 December 2020

Accepted: 25 January 2021

Published: 28 January 2021

Publisher's Note: MDPI stays neutral with regard to jurisdictional claims in published maps and institutional affiliations.

Copyright: (C) 2021 by the author. Licensee MDPI, Basel, Switzerland. This article is an open access article distributed under the terms and conditions of the Creative Commons Attribution (CC BY) license (https:// creativecommons.org/licenses/by/ $4.0 /)$
Independent Scholar, New Delhi 110 070, India; amiyasen1@gmail.com

In 2002, the Government of India published a Universities Handbook based on a survey of 273 institutions of higher learning in India (excluding the 12,000-odd colleges that existed at the time) and of their academic programs. For the authors of this report, one of the official terms of reference was to determine just how many of these institutions offered anything resembling a course on religious studies. The Handbook reveals that only about $5 \%$ of the institutions so surveyed offered such courses. Of these, some dealt with the specialized study of a particular religion only. Thus, there were 13 universities offering specialized courses in the study of Islam, including both undergraduate and graduate courses and 3 graduate Buddhist study programs listed, but no supporting undergraduate courses. Quite conspicuous by its absence was a course on Hinduism on any level. Prima facie, this looks astonishing in a country where Hindus constitute an overwhelming majority. Ironically, even Oxford (UK) has an academic center for the study of Hinduism, just as it does for Islam and for Jewish and Hebrew Studies.

The common understanding of the matter was that this followed from the state policy of upholding the secular credentials of the Indian Constitution and, more generally, the underlying ecumenical spirit of the Indic civilization and culture. On one level, this is an odd explanation to offer. In the first place, given the orthopraxy characteristic of Hinduism itself, was it reasonable to keep it out of reckoning? Second, did someone naively assume that the onus of keeping inter-faith tensions in check rested on the majority community only? Third, the exclusion of Hinduism as a field of study would appear to be at fault historically since, in their quest for reformist modernization, several non-Hindu faiths and cultures have redefined their boundaries in relation to Hinduism. Reform, in this instance, postulated an inner unity of faith and praxis, whether real or imagined, within a given community. For Muslims and Sikhs in particular, Hinduism was seen to be a "corrupting" influence, and reformist ventures, therefore, implied the careful cleansing and excision of these influences. On the contrary, for the Hindus themselves, this was essentially an internal squabble with an enemy that was located deep inside and not outside itself.

Thanks partly to Nehruvian ideology that reigned in the 1960s and 1970s and the turn that the social sciences increasingly took towards left-liberal ideology, the term "religion" became almost taboo in some circles. Very few Universities had anything close to an academic study of religion. For the contemporary Indian ruling class and some supporting ideologues, the study of religion was deemed anachronistic and bred only inter-faith hostility. This followed from the gratuitous assumption that religious differences were not mischievous expressions of communalism but its underlying cause. Not surprisingly, my generation has not witnessed the birth of an Indian academic journal that specialized in religious studies in general, not to speak of Hinduism. Currently, the most widely read and respected journals related to the study of Hinduism are all located in Western academia.

When, therefore, the Religions office graciously invited me to edit a Special Issue on Hinduism, I was seized with elated excitement, but which soon changed into disappointment. Though happy to have been so invited, I was unsure if I would have within reach an adequate number of Indian historians who may be willing to meaningfully contribute to the project. Of the eight scholars who have contributed to this volume, three are based 
outside India and of the eight again; only three are by training professional historians. On one level, surely, this only confirms the continuing global interest in Hinduism and happily throws open an enterprise such as this one to cross-fertilization from allied disciplines. On another, this also speaks for the poverty of scholarly interest within the Indian academia in the matter of considering religion as a field of serious academic study.

The eight papers that make up this Special Issue have much in common. In one form or another, they all question settled opinions, interrogate the underlying malleability of social idioms and experiences and critique simplistic and unproblematized representations of cultural praxis. Happily, some of these reveal overlaps in themes, which then makes it possible to construct broad groupings of the papers included. Jeffery Long, Arpita Mitra and Swami Medhananda engage with the Ramakrishna-Vivekananda tradition; Ravi M. Gupta and Santanu Dey bring up critical questions connected with Vaishnava history and culture; Ankur Barua, Hina Khalid and Nandini Bhattacharya raise pertinent questions regarding cross-cultural exchanges. A paper that is unique in its intellectual interest is that by Varuni Bhatia, which examines the role of the digital media in advancing popular Hinduism today.

Arpita Mitra (From Nitya to Lila. Sri Ramakrishna and Vedanta) critically examines an older question about whether or not Ramakrishna's preaching and parables could justly be associated with the Vedanta school of Indian philosophy. She rightly cites scholars like Zimmer and Neevel, who, contrary to hagiographers like Swami Saradananda of the Lilaprasanaga fame, claim that the saint was closer to the Tantric tradition than to Vedanta. She also disputes two other postulates commonly used in academic studies related to the Ramakrishna-Vivekananda movement. The first of these is about the validity of attaching the prefix "neo" to Vedanta to indicate the hermeneutic changes produced within this school by Hindu thinkers of the colonial era. The second pertains to a critique of the position adopted by scholar Ayon Maharaj (later Swami Medhananda, a contributor to this volume) in his studies of Ramakrishna's religious ecumenism. Mitra finds Maharaj to have come up with an "over-interpretation", but fails to clinch the issue by not adding two points of substance. One is apt to agree with Mitra in doubting if Ramakrishna's words could indeed be taken at their face value and not placed within the framework of an older Hindu discourse. However, what Mitra may have more pointedly disputed is the fact that beginning with Rammohun Roy, no major Hindu thinker of the modern era has claimed innovation in religious thought. Furthermore, questionable is Maharaj's recurring use of the word "harmony" / "harmonize" in the context of Ramakrishna's religious discourse, which Mitra may have justly faulted. Here, both Maharaj and his critic overlook the fact that Ramakrishna fully respected existing boundaries between religions and did not take these to be porous or inter-penetrable. Thus, when training in Sufi Islam, he refused to visit the temple to the goddess Kali where he otherwise served as a priest. "Harmonize" seems curiously inept in describing Ramakrishna's upholding the equal validity of all religions but never suggesting that various religious traditions could be harmoniously fused. Hitherto, Maharaj's position, as I also recall, has been that Ramakrishna accepted the validity of all traditions as traditions but accepted the teachings of each only selectively. This is inconsistent with Ramakrishna's belief that religions were not the creation of men but of God. Was it pure mischief on God's part then, to introduce qualitative differences within religions, thereby deliberately leading some men and women to "false" or "unclean" paths? In Ramakrishna's own view, as I understand it, this could have been possible only with reference to the concept of lila or the inscrutable play of God. However, neither Mitra nor Maharaj cares to suggest as much. Mitra's own paper suffers from the reluctance to overcome the common error of using the terms Vedanta and Advaita Vedanta interchangeably. Ramakrishna's grounding in Vedanta, if this term is taken in its composite or undifferentiated form, cannot be a matter of any dispute; his association with Advaita, on the other hand, would be subject to qualifications. I have myself wondered at times if by the term "Advaita" Ramakrishna simply meant the grounding of all reality, consciousness or experiences in God and not the intricacies of non-dualist metaphysics. 
Swami Medhananda's paper (Was Swami Vivekananda a Hindu Supremacist? Revisiting a Long-standing Debate) is similarly a recapitulation of an older debate but specifically critiques Jyotirmaya Sharma's work A Restatement of religion. Swami Vivekananda and the making of Hindu Nationalism (2013). In Medhananda's view, Sharma's work suffers from both methodological flaws and some specious arguments. Allegedly, Sharma only selectively uses Vivekananda's thoughts on Vedanta, placing them outside their historical and ideological contexts, leading to a degree of distortion. In suggesting that the universalism of Vivekananda lay not in privileging Advaita but in his advocating the equal validity of the four yogas, Medhananda anticipates a key argument in the paper by Jeffery Long in this collection. A problematic aspect of Medhananda's paper, though, lies in his claim that rather than feed Hindu nationalism, as Sharma alleges, Vivekananda's intention was to provide "an ethical and spiritual foundation" for Indian nationalism. Prima facie, this appears difficult to reconcile with the Swami's emphatic rejection of the political praxis, his reluctance to involve the Ramakrishna Math and Mission in active political work, subsequently leading even Sister Nivedita to sever her connection with this organization. In hindsight, the problems with "spiritualizing" politics are as evident in the case of Vivekananda as subsequently with Gandhi.

Jeffery Long's (A Complex Ultimate Reality: The Metaphysics of the Four Yugas) reinforces the arguments of Medhananda in two related ways. First, he argues for establishing the right context for the study of Vivekananda's evolving thoughts on Vedanta. Second, as noted above, he finds Vivekananda's plurality originating not in his advocacy of Advaita as is commonly believed, but in the spiritual freedom to choose from any of the four yogas. Long finds Vivekananda's approach comparable to the "deep religious pluralism" of the philosopher Whitehead and to the open-ended approach to Truth found in the syadvada/anekantavada perspective of the Jains. Vivekananda's early study of the Vedanta is well documented, and it would have been interesting to know though just where Jain philosophical influences, if any, may have been derived from. Two of Long's arguments that I found less persuasive are first, the claim that Vivekananda did not separate the yogas from religion and second, the assertion that Vivekananda was not the Kali worshipper that Ramakrishna was. Vivekananda's Karma Yoga, as I recall, dissociates it from any concern with God or religion in a manner reminiscent of the Hindu thinker Bankimchandra Chattopadhyay who, in his work, Dharmatattwa concluded on the astonishing note that patriotism was the highest dharma! Admittedly, in his early life, Vivekananda resisted Kali worship, possibly on account of his Brahmo antecedents, but subsequently wrote poems to Kali and persuaded Nivedita to deliver two successive lectures on this Goddess in Kolkata, much to the consternation of Hindu rationalists and reformers.

An interrogation into the fluidity of conceptual or doctrinal boundaries between traditions quite persuasively appears in the paper by Ravi M. Gupta (Why Sridhara Svami? The Making of a Successful Sanskrit Commentary). The question that Gupta poses before us is why, notwithstanding the Advaitin credentials of the commentator Sridhara Svami, he was widely accepted by the Vaishnava tradition, which was otherwise quite critical of non-dualist philosophy. Gupta rightly observes the rather paradoxical play of creativity and restraint, dogmatism, but also the purposive sharing of common religious space within the Hindu philosophical tradition, a liminal playfulness that often cuts across religious and philosophical boundaries. The medieval Vaishnava mystic, Chaitanya, who strongly critiqued non-dualism, himself belonged to the Dasnami order of monks and had22 Advaitc sanyasis as companions. Further, the Bhagavat Purana, a primary sourcebook for Vaishnavas, has strong elements of Advaitic thought and in medieval India, at least three figures known for their Krishna-bhakti (Madhavendra Puri, Iswar Puri and Madhusudan Saraswati) were also Dasnami monks and prominent non-dualist thinkers.

Sanatanu Dey's paper (Locating Vishnupriya in the tradition. Women, Devotion and Bengali Vaishnavism in Colonial times) brings out the changing role of the woman within the movement. Medieval Vaishnavism was characterized by a strongly Brahmanical disdain for the woman and the threat from female sexuality. As with certain quotidian cults, it 
was also known to use the woman instrumentally in sadhana or spiritual praxis. These tendencies, as Dey argues, came to be reconfigured in the colonial era, whereby eroticized feminization was channeled into more sanitized paths of domesticity and conjugality. The paper analyses how Visnupriya, the widowed second wife of Chaitanya, came to eventually acquire the status of a cult leader by the late 19th century. There was a promising case here, I felt, for Dey to examine comparable developments within the Ramakrishna Movement with the widowed Sarada Devi also assuming the status of the Sangha Janani (Holy Mother to members of the organization). I had reason also to disagree with Dey's conflating "Bengal (or Gaudiya) Vaishnavism", the school associated with Chaitanya, with "Bengali Vaishnavism", which was a more amorphous religious formation accommodating diverse devotional cultures within the world of Krishna bhakti.

It was left to Nandini Bhattacharya (Behold the Human! Reading life Narratives in Times of colonial Modernity) and the team of Ankur Barua and Hina Kahlid (The Feminization of Love and the Indwelling of God. Theological Investigations across Indic Contexts) to alert us to the problematic aspects of studying cross-cultural exchanges. Bhattacharya's paper is a comparative study of Seeley's revisionist characterization of Jesus and Bankimchandra Chattopadhyay's Krishnacharitra. The latter was both a remarkable contribution to the emerging genre of biographies and an attempt at both historicizing and humanizing God. In her paper, Bhattacharya makes the illuminating point that Indian modernity was not constituted through a simplistic internalization of desacralized reason or an unproblematic separation of the religious and the secular. This recalls to mind Bankim's own argument that modern Western education had, in fact, only reinforced his belief in the idea of God descending on earth as a man. Rammohun, if I may further complicate this argument, rejected the concept of incarnation as irrational but rebelled against what he called the "surfeit" of reason. Apparently, contrary to what Bhattacharya suggests, the two versions of Krishnacharitra that Bankim himself was persuaded to compare and contrast by way of registering his changing views on the subject are not those of 1884 and 1886, but 1884 and 1892, respectively.

Barua and Khalid argue much in the same vein, pointing to the recurring dialogic exchanges between otherwise seemingly opposed religious traditions. This, they do through a deeply insightful study of love imageries in the religious lives of both Sufi mystics and Hindu devotees. Their thesis rests on two central arguments: first that in the study of religions, it is important to avoid both extremes of postulating fixed binaries and naïve homogenization and second, that modern labels cannot be reasonably extrapolated on matters belonging to the pre-modern. It would be interesting to explore, though, if Sufi love imageries were always expressed through the feminization of the male devotee. I am reliably informed that the opposite is also true whereby the macho Sufi mystic is given to display his mardaangi towards God, his beloved.

Finally, we turn to the paper by Varuni Bhatia (Shani on the Web: Virality and Vitality in Digital Popular Hinduism). This is a highly interesting study of what may be loosely called the development of "digital religiosity" in recent times, emerging from what is clearly a revolution, perhaps the biggest and the most far-reaching since the Industrial Revolutions, and the ways in which it has impacted human life and interpersonal communication. In this paper, Bhatia examines the digital presence of the Hindu quasi-god, Shani, corresponding to the planet Saturn, generally taken to be a malefic influence in Hindu astrology and one which the Hindus have always been anxious to appease. The paper interrogates what it means to engage with a "sacred" object in a virtual realm and how technology is now increasingly constitutive of everyday Hindu religious practices. This is an interrogation which, I thought, still allows for interim observations rather than definitive conclusions. The cult of Shani is now vastly popular, making it possible to construct flourishing shrines and pilgrim towns dedicated to the god and where the devotee may actually relate to Shani as an embodied deity. This appears to be an aspect that has been visibly changing. Not long back, it was a common occurrence on Saturdays to come across visibly poor, lower caste girls, stationed at busy intersections and market places, carrying metallic cans inside 
which was immersed in mustard oil, a crude representation of Shani. The association of such girls with the cult is meaningful since Shani represents menials and manual workers, and presumably, when upper class devotes patronizingly dropped a coin or two into the oil can, they drew vicarious pleasure at simultaneously mitigating Indian poverty and keeping at bay a potentially malevolent force from their otherwise successful lives! If only she looked more carefully, Bhatia might discover that here, the notion of "popular religion" may have more to do with the number of practitioners than some particular class. Shani worship is, in one sense, a classless phenomenon affecting those always in fear of losing something and averting at all costs some misfortune coming their way from the "evil eye" of this maverick god. The question to also ask here is whether digital religiosity too draws authority from some publicly respectable and acknowledged source. Does divine embodiment visible in smart phones or obtained by the click of a mouse have a value comparable to that of a conventionally consecrated deity? Finally, may we justly draw a link between the holy and the simply auspicious? Is there something truly sacred about Shani, or does it metaphorically represent the anxiety to conquer failure and recurring obstacles that most of us must negotiate in our daily lives?

I have enjoyed editing this collection of papers and trust that our readers, too, will enjoy reading them.

Funding: This research received no external funding.

Conflicts of Interest: The author declares no conflict of interest. 